\title{
Depression in Pancreatic Cancer: Sense of Impending Doom
}

\author{
Martina Mayr Roland M. Schmid \\ Internal Medicine II, Klinikum rechts der Isar, Technical University of Munich, Munich, Germany
}

Pancreatic cancer is still one of the malignancies with the worst prognosis and associated with a high prevalence of depression. This relationship was already described about 70 years ago, but is still poorly understood $[1,2]$. Dealing with this subject, one pivotal question remains: is this depression a feature of pancreatic cancer per se or is it rather a response to the experience of gradual loss of strength and body weight in patients with a life-threatening diagnosis?

In this issue of Digestion, Lin et al. [3] report on the incidence of depression and quality of life in patients suffering from pancreatic cancer prior to surgery or chemotherapy comparing their cohort with patients with gastrointestinal cancer of other origin. All 262 recruited patients met the inclusion criteria which postulated them to be inpatients with an assured cancer diagnosis (pancreatic, liver, esophageal, gastric or colorectal cancer) and without any history of psychological or psychiatric diseases. Clinical features like age, gender, TNM stages and treatment strategy were well balanced. The incidence of depression was significantly higher in patients with pancreatic carcinoma than in those with other cancers of the digestive system. $78 \%$ of the pancreatic cancer patients suffered from depression and $60 \%$ of liver cancer patients, but only $36 \%$ of gastric cancer, $24 \%$ of esophageal cancer and $19 \%$ of colon cancer patients. The differences between pancreatic carcinoma and the other gastrointesti- nal cancers were statistically significant [3]. These findings are consistent with the data published so far.

After the initial description in 1931, several studies have reported on the association between pancreatic cancer and the triad of anxiety, depression and 'sense of impending doom' $[1,2,4,5]$. Remarkably high incidence rates were affirmed by a study in 1993 which showed depressive symptoms in $71 \%$ of the explored pancreatic cancer patients and 'anxiety-related symptoms' in $48 \%$ of the patients [6]. In a comprehensive review, Massie [7] referred to the prevalence of depression in pancreatic cancer between 33 and 50\%. Different from the study by Lin et al. [3], some trials performed prior to confirmation of cancer diagnosis observe psychological symptoms preceding somatic disorders $[8,9]$. Therefore, a discussion about 'mental symptoms as an aid in early diagnosis of pancreatic cancer' was started [10-12].

This refers to the initial question for the scientific background concerning the bidirectional relationship between depression and pancreatic cancer. Lin et al. [3] documented by the presented analysis a linkage to TMN stages and intended treatments (chemotherapy or surgery) representing a patient's assumed life expectancy and hope for recovery. This burden of emotional distress exceeding the patient's capability of coping with tumor disease frequently results in development of major depression. In contrast, reporting high incidence rates for

\section{KARGER}

Fax +4161306 1234 E-Mail karger@karger.ch www.karger.com
(C) 2010 S. Karger AG, Base $0012-2823 / 10 / 0821-0001 \$ 26.00 / 0$

Accessible online at: www.karger.com/dig
Roland M. Schmid, Universität München, Klinikum rechts der Isar

II. Medizinische Klinik und Poliklinik der Technischen Universität München

Ismaninger Strasse 22, DE-81675 München (Germany)

Tel. +49 894140 2250, Fax +498941404871

E-Mail roland.schmid@lrz.tu-muenchen.de 
depression in pancreatic cancer, Lin et al. also mentioned that 'there was no statistically significant difference in knowing the diagnosis or not'. Among these patients, depression developed independent of awareness of 'impending doom'. According to this observation it is still under discussion whether pancreatic cancer induces depression or whether depression enhances the risk of tumor development $[4,13]$.

Evaluating depression incidence rates, there is still no consensus about the appropriate instrument to identify depression in cancer patients, especially to differentiate between major depression and 'quite normal' psychological distress while coping with cancer diagnosis. The general classification complies with the Diagnostic and Statistical Manual of Mental Disorders DSM-IV. Lin et al. [3] used HAMD-24 as the rating scale for depression. This Hamilton Rating Scale for Depression has been a standard instrument for peer assessment of depression's severity since 1970 [14], but HAMD as well as CPRS (Comprehensive Psychopathological Rating Scale) or MADRS (Montgomery-Åsberg Depression Rating Scale) [15] are in fact no diagnostic instruments for depression but measures of illness severity. It is still discussed whether these rating scales are suitable for primary identification of major depression [16-18]. Self-assessment instruments like Beck's Depression Inventory could support a reliable identification. To avoid in particular an immoderate influence of somatic symptoms in screening for depression, the Hospital and Anxiety Depression Scale has been designed [18]. The great influence of anxiety and depression on life quality emerges in several studies [18-20]. Meanwhile, assessment of life quality is highly standardized enabling us to judge treatment benefit. In the current tri- al by Lin et al. [3], EORTC QLQ-C30 was employed additionally in patients with pancreatic cancer who were evaluated by the EORTC QLQ-PAN-26 questionnaire. In the group of patients with pancreatic cancer the most significant impairment was denoted in scores of physical, role, emotional and cognitive functioning with a special impact on social functioning. The score of symptom scales, in particular fatigue and pain, was also significantly higher in the pancreatic cancer group, but there was no evidence for a statistically significant difference in the global QLQ scale. Comparing pancreatic cancer patients with and without depression, a significant deterioration of life quality was shown. According to these findings, patients with pancreatic cancer and depression suffered fatigue, pain and appetite loss more than depressive patients with other gastrointestinal malignancies [3]. Accordingly, the association between pain and depression is well documented $[21,22]$ and chronic pain is undoubtedly a crucial factor in judging quality of life [19].

Though the question for the link between pancreatic cancer and depression remains unanswered, review of the data published so far confirms the utmost importance of paying attention to depressive reactions in pancreatic cancer patients and care for adequate treatment. The article presented by Lin et al. [3] demonstrating the extraordinarily high incidence rates of pancreatic cancerrelated depression and its strong impact on quality of life is an important contribution to these considerations. Further investigation and interventional trials in particular are required in order to determine this extraordinary correlation of psychological and pathophysiological findings.

\section{References}

1 Makrilia N, Indeck B, Syrigos K, Saif MW: Depression and pancreatic cancer: a poorly understood link. JOP 2009;10:69-76.

2 Yaskin J: Nervous symptoms at earliest manifestations of cancer of the pancreas. JAMA 1931;96:1664-1668.

-3 Jia L, Jiang S-M, Shang Y-Y, Huang Y-X, Li Y-J, Xie D-R, Huang K-H, Zhi F-C: Investigation of the incidence of pancreatic cancer-related depression and its relationship with the quality of life of patients. Digestion 2010; 82:4-9.

-4 Carney CP, Jones L, Woolson RF, Noyes R Jr, Doebbeling BN: Relationship between depression and pancreatic cancer in the general population. Psychosom Med 2003;65: 884-888.

\footnotetext{
5 Fras I, Litin EM, Pearson JS: Comparison of psychiatric symptoms in carcinoma of the pancreas with those in some other intra-abdominal neoplasms. Am J Psychiatry 1967; 123:1553-1562.

-6 Green AI, Austin CP: Psychopathology of pancreatic cancer. A psychobiologic probe. Psychosomatics 1993;34:208-221.

7 Massie MJ: Prevalence of depression in patients with cancer. J Natl Cancer Inst Monogr 2004;57-71.

-8 Jacobsson L, Ottosson JO: Initial mental disorders in carcinoma of pancreas and stomach. Acta Psychiatr Scand Suppl 1971;221: 120-127.

-9 Joffe RT, Rubinow DR, Denicoff KD, Maher M, Sindelar WF: Depression and carcinoma of the pancreas. Gen Hosp Psychiatry 1986; 8:241-245.

10 Fras I, Litin EM, Bartholomew LG: Mental symptoms as an aid in the early diagnosis of carcinoma of the pancreas. Gastroenterology 1968;55:191-198.

11 Passik SD, Roth AJ: Anxiety symptoms and panic attacks preceding pancreatic cancer diagnosis. Psychooncology 1999;8:268-272.

12 Griffeth BT, Mehra A: Panic as a harbinger of pancreatic cancer. Psychosomatics 2008; 49:538-539.

13 Hamilton M: Development of a rating scale for primary depressive illness. Br J Soc Clin Psychol 1967;6:278-296.
} 
14 Montgomery SM: Depressive symptoms in acute schizophrenia. Prog Neuropsychopharmacol 1979;3:429-433.

-15 Passik SD, Lundberg JC, Rosenfeld B, Kirsh KL, Donaghy K, Theobald D, Lundberg E, Dugan W: Factor analysis of the Zung SelfRating Depression Scale in a large ambulatory oncology sample. Psychosomatics 2000; 41:121-127.

16 Kathol RG, Mutgi A, Williams J, Clamon G, Noyes R Jr: Diagnosis of major depression in cancer patients according to four sets of criteria. Am J Psychiatry 1990;147:1021-1024.
7 Angelino AF, Treisman GJ: Major depression and demoralization in cancer patients: diagnostic and treatment considerations. Support Care Cancer 2001;9:344-349.

18 Fazal S, Saif MW: Supportive and palliative care of pancreatic cancer. JOP 2007;8:240253.

19 McDaniel JS, Musselman DL, Porter MR, Reed DA, Nemeroff CB: Depression in patients with cancer. Diagnosis, biology, and treatment. Arch Gen Psychiatry 1995;52:8999.
20 Massie MJ, Gagnon P, Holland JC: Depression and suicide in patients with cancer. J Pain Symptom Manage 1994;9:325-340.

21 Kelsen DP, Portenoy RK, Thaler HT, Niedzwiecki D, Passik SD, Tao Y, Banks W, Brennan MF, Foley KM: Pain and depression in patients with newly diagnosed pancreas cancer. J Clin Oncol 1995;13:748-755.

22 Spoletini I, Gianni W, Repetto L, Bria P, Caltagirone C, Bossu P, Spalletta G: Depression and cancer: an unexplored and unresolved emergent issue in elderly patients. Crit Rev Oncol Hematol 2008;65:143-155. 